\title{
Food abundance, kittiwake life histories, and colony dynamics in the Northeastern Pacific: implications of climate change and regime shifts
}

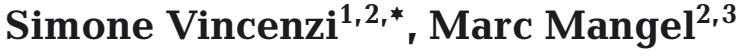 \\ ${ }^{1}$ Dipartimento di Elettronica, Informazione e Bioingegneria, Politecnico di Milano, Via Ponzio 34/5, 20133 Milan, Italy \\ ${ }^{2}$ Center for Stock Assessment Research and Department of Applied Mathematics and Statistics, University of California, \\ Santa Cruz, CA 95064, USA \\ ${ }^{3}$ Department of Biology, University of Bergen, PO Box 7803, 5020 Bergen, Norway
}

\begin{abstract}
Black-legged kittiwakes Rissa tridactyla in the Northeastern Pacific will increasingly experience climate-induced changes in the variability of forage fish, which will influence both the quantity and quality of food and may thus alter the population dynamics of kittiwake colonies. However, the relative roles of individual- and population-level traits in determining colony dynamics and risk of extinction are still unclear. We combined models of components of the Pacific kittiwake life history with empirical data linking physiological stress and food abundance to provide a unified treatment of kittiwake colony dynamics. We simulated the dynamics of colonies with high, medium and low responsiveness of productivity to variation in nutritional stress in breeding birds, using data from Alaskan colonies. We found that the risk of quasi-extinction strongly decreased with a moderate increase in the potential number of yearly immigrants. Prebreeding mortality as a function of growth during development had only a marginal role in determining median number of breeding pairs over simulation time. We predict that temporal autocorrelation of colony-wide average productivity and high nutritional stress, particularly if consistent over time, will increase quasi-extinction risk. Our work shows that colonies with low productivity have little chance of persistence even when survival of pre-breeding and breeding birds is high, and that the nature of the temporal auto-correlation of food conditions and productivity is crucial to understand the effect of environmental fluctuations, regime shifts, and climate change on population dynamics of kittiwakes. We use the model to highlight the most valuable future empirical studies.
\end{abstract}

KEY WORDS: Black-legged kittiwakes - Food abundance - Corticosterone - Immigration · Temporal auto-correlation

\section{INTRODUCTION}

The ways in which individual and colony dynamics of seabirds will change in response to climate change are still unclear. Concomitant with major climate changes occurring in the North Pacific ocean over the last few decades (Anderson \& Piatt 1999, Hunt et al. 2008, Mueter \& Litzow 2008), some seabird colonies in the continental shelf areas of the central and southeastern Bering Sea declined in size, while others increased (Springer 1998, Hunt et al. 2002, Byrd et al. 2008a). The hypothesis with the best support is that the population dynamics of seabirds in these colonies are differently affected by climateinduced changes in the physical environment, which controls forage patch dynamics (i.e. spatial or tempo- 
ral heterogeneity of food abundance and quality) and may thus alter both the quantity and quality of food available to the birds (Ciannelli et al. 2005, Byrd et al. 2008a, Coyle et al. 2011).

Scarce availability of food clearly reduces productivity in Pacific kittiwake Rissa tridactyla colonies (Gill \& Hatch 2002), and dramatic fluctuations in colony size at annual and decadal scales are relatively common (Piatt \& Harding 2007). Kitaysky et al. (2010) and Satterthwaite et al. (2010) showed that nutritional stress during reproduction affects both survival and reproduction in kittiwakes living in Alaskan colonies. In addition, kittiwakes living in different colonies had different responses to nutritional stress, possibly indicating variation in strategies among individuals living in different colonies (e.g. relatively fast living - reproduction at a younger age and higher reproductive effort—vs. slow living) (Kitaysky et al. 2010, Schultner et al. 2013).

The ability to predict (vs. a retrospective analysis of) population or colony responses (here we use the 2 terms interchangeably) to climate-induced modification of the environment will be valuable for conservation efforts. Jenouvrier et al. (2009) argued that to project a population's response to future climate change we should estimate the effects of climate on vital rates, project future climate conditions, and model these effects within a population dynamics framework. Unfortunately, quantifying the effects of climate on vital rates and the projection of future climate conditions, especially in regions and habitats where high variability is the norm rather than the exception (such as the Polar regions), is often not possible. The analysis of models of population dynamics with different parameterizations provides key insights into the most important traits (e.g. fecundity, survival), stages (e.g. pre-breeding, post-breeding) or conditions (e.g. food availability, weather conditions) for various performance measures for a single or a group of seabird colonies. Thus, understanding the potential effects of climate change is a subject best approached by a combination of theoretical and empirical methods in which the empirical work guides the theoretical constructs, and the modeling identifies key pieces of empirical information that are required for advancing understanding.

Here, we use an Individual-Based Model (IBM; Grimm \& Railsback 2005) to analyze kittiwake colony dynamics under various assumptions about kittiwake life-history strategies and individual- and colonylevel responses to nutritional stress. We use the link between food abundance, stress hormones and pro- ductivity found for Alaskan colonies (Kitaysky et al. 2010, Satterthwaite et al. 2010) to simulate mean productivity at the colony level, and adult (i.e. postbreeding) survival. We then complete the life cycle by modeling the relationships between (1) sex, (2) social rank and (3) body growth during the nesting phase and post-fledging survival and age at recruitment (Vincenzi et al. 2013). We thus offer the first published model of the full Pacific kittiwake life cycle.

The IBM allows us to assess the relative importance of (1) temporal variation in food abundance, (2) mean productivity and sensitivity of productivity to variation in food abundance mediated by nutritional stress in breeders, (3) potential number of birds immigrating each year from other colonies and (4) mortality of pre-breeders (i.e. birds that still have to recruit) for (a) the risk of quasi-extinction and (b) colony size over $50 \mathrm{yr}$.

\section{MATERIALS AND METHODS}

\section{Species description}

Kittiwakes occur in both the North Atlantic and North Pacific Oceans, and exhibit differences in life histories and demographic traits according to a latitudinal gradient (Coulson 2011). Most of the information at the colony and individual levels comes from colonies in the North Atlantic (Coulson 2011), while less information is available for colonies in the North Pacific (Kitaysky et al. 2000, Suryan 2000, Piatt 2002, Piatt \& Harding 2007, Vincenzi \& Mangel 2013). Adult (i.e. post-breeding) survival is generally high, and individuals may reach age 25 or older (Coulson 2011). Annual reproductive output is low (Atlantic colonies are on average more productive than Pacific colonies, a common trait for species distributed in both oceans; Suryan et al. 2009). When more than 1 egg hatches, first-, second- and third-hatched chicks are recorded as A-, B- and C-chicks, respectively; if only a single chick hatches, it is commonly recorded as singleton.

After fledging, Pacific kittiwakes spend between 3 and $11 \mathrm{yr}$ at sea as pre-breeders before recruiting to the colony to breed (Vincenzi et al. 2013). Breeding kittiwakes show high overall site fidelity, although emigration to colonies other than the natal one is common. The food of breeding kittiwakes varies markedly from year to year both in quality and quantity, and is one of the main determinants of productivity. 


\section{Model of individual and colony dynamics}

Complete information on vital rates, life histories, and population dynamics is not available for any of the Pacific kittiwake colonies. A number of previous studies on Northeastern Pacific kittiwakes provide important information on parts of the kittiwake life history, and modeling allows us to put them together for a full picture of the life cycle and of life histories of Pacific kittiwakes.

Kitaysky et al. (2010) related an index of fish abundance in the proximity of the colony and stress (levels of corticosterone, CORT, in breeding birds) and Satterthwaite et al. (2010) related CORT levels and the probability that a breeder 'disappears' from the colony (i.e. does not return to the natal colony, which is 'apparent' mortality). Vincenzi \& Mangel (2013) connected chick growth and survival from hatching up to first breeding. Vincenzi et al. (2013) linked food abundance during development (for which growth rates of chicks can be considered a proxy) and social rank to the onset of reproduction.

In this paper, we combine these sub-models and results from other empirical studies to provide a complete life-cycle model of kittiwakes in the Northeastern Pacific. With this full life cycle model, we can understand colony-level responses to changing climate and environmental conditions, represented by changing abundance of food. We now describe the various model components (Fig. 1) and justify our choice of parameter values (Table 1).

Foraging conditions. Kitaysky et al. (2010) found that nutritional stress during reproduction affected both survival and reproduction of kittiwakes living in Gull, Duck and Middleton Islands (Alaska). Nutritional stress was negatively related to catch per unit effort (CPUE; fish trawl $^{-1}$ ) in the proximity of the colonies (Fig. 2). Although food availability for seabirds is not a simple function of forage fish abundance, but rather a complex suite of factors including the amount, quality, and location (including depth) of prey (Jodice et al. 2006, Benoit-Bird et al. 2011), the relationship is compelling. We thus use the range of CPUE values in Kitaysky et al. (2010) as an index of food abundance and a proxy of food availability for kittiwakes.

The ecosystem effects of climate change-induced warming trends and loss of sea ice in the Northeastern Pacific are still uncertain. Warmer conditions favor demersal species of lesser importance for kittiwakes (Hatch 2013), and poor foraging conditions may thus persist for a long time in the case of a consistent warming trend. However, part of the uncer-

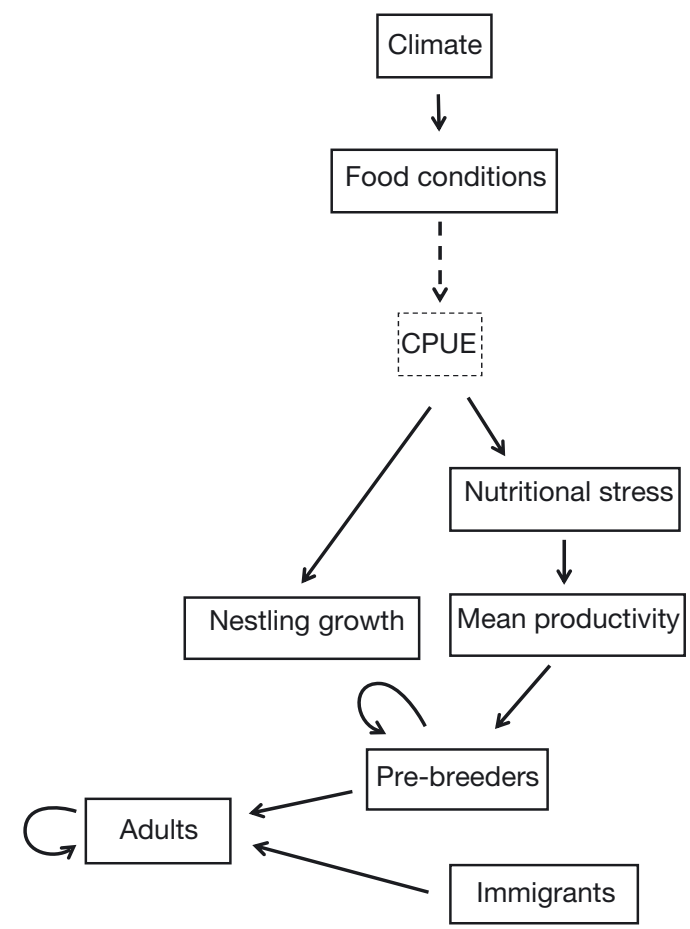

Fig. 1. Schematic representation of the model of population dynamics for black-legged kittiwake Rissa tridactyla. Climate and oceanographic conditions determine food conditions in the proximity of the colony, for which catch per unit effort (CPUE) operates as a proxy in our model (as described by the dashed arrow). Food conditions near the colony have substantial effects on nutritional stress of adults and growth of nestlings. Mean colony-wide productivity is a function of nutritional stress and colony type. Annual survival of prebreeders is a function of their growth during the nestling phase, sex, and maximum mortality, while their sexual maturation depends on social rank. Variation in adult survival is mostly determined by nutritional stress at breeding. Each year a variable number of adult kittiwakes immigrate into the colony

tainty about the ecosystem effects of warming trends in the Northeastern Pacific is due to the interaction between warming trends and regime shifts (Hare \& Mantua 2000), which in the North Pacific have been both observed in recent times from oceanographic data and inferred from paleo-ecological records for the past centuries. Regime shifts in the Northeastern Pacific generally imply that multiple years of poor food conditions are then followed by multiple years of good food conditions (Hatch 2013).

In order to test the responses of kittiwake colonies to possible future scenarios of food conditions, we simulate the temporal pattern of $\log _{10}$ (CPUE) by 1 of 3 methods:

(1) Scenario $R_{\mathrm{F}}$ (poor): Randomly drawing $\log _{10}$ (CPUE) at each time, $t$, from a uniform distribution bounded between the minimum $\left(\mathrm{CPUE}_{\mathrm{MIN}}\right)$ and 
Table 1. Parameters of the Individual-Based Model of kittiwake colony dynamics. We report value of the parameters or range in case of multiple scenarios investigated. ARIMA: Auto-Regressive Integrated Moving Average; CPUE: catch per unit effort; CORT: corticosterone

\begin{tabular}{|c|c|c|c|c|c|}
\hline Parameter & Value(s) & Sub-model & Explanation & Eq. & References \\
\hline$p$ & 0.85 & \multirow{2}{*}{ ARIMA for $\log _{10}(\mathrm{CPUE})$} & Auto-regressive part of ARIMA model & \multirow[t]{2}{*}{-} & \multirow[t]{2}{*}{ This study } \\
\hline$\rho$ & 3 & & Rate of exponential innovations & & \\
\hline $\begin{array}{l}\log _{10}\left(\mathrm{CPUE}_{\mathrm{MIN}}\right) \\
\log _{10}\left(\mathrm{CPUE} \mathrm{E}_{\mathrm{MAX}}\right)\end{array}$ & $\begin{array}{c}1 \\
3.5\end{array}$ & $U$ for $\log _{10}(\mathrm{CPUE})$ & Min. and max. of $\log _{10}(\mathrm{CPUE})$ & - & This study \\
\hline $\begin{array}{l}\alpha_{\mathrm{CPUE}} \\
\beta_{\mathrm{CPUE}} \\
\sigma_{\mathrm{CPUE}}\end{array}$ & $\begin{array}{c}1.5 \\
-0.36 \\
0.125\end{array}$ & $\log _{10}(\mathrm{CORT})$ & $\begin{array}{l}\text { Parameters of the linear } \\
\text { model to determine annual } \\
\log _{10}(\mathrm{CORT})\end{array}$ & 1 & Kitaysky et al. (2010) \\
\hline $\begin{array}{l}\alpha_{\mathrm{CORT}} \\
\beta_{\mathrm{CORT}}\end{array}$ & $\begin{array}{l}-2.399 \\
0.0803\end{array}$ & $m(\mathrm{CORT})$ & $\begin{array}{l}\text { Parameters of the logistic } \\
\text { model for } m \text { (CORT) }\end{array}$ & 3 & $\begin{array}{l}\text { Satterthwaite et al. } \\
\text { (2010) }\end{array}$ \\
\hline $\begin{array}{l}\beta_{\mathrm{SC}}\left(\mathrm{Col}_{\mathrm{H}}\right) \\
\beta_{\mathrm{SC}}\left(\mathrm{Col}_{\mathrm{M}}\right) \\
\beta_{\mathrm{SC}}\left(\mathrm{Col}_{\mathrm{L}}\right)\end{array}$ & $\begin{array}{l}-0.63 \\
-0.36 \\
-0.01\end{array}$ & \multirow[t]{3}{*}{$\bar{C}$} & $\begin{array}{l}\text { Change of average productivity }(\bar{C}) \text { for } \\
\text { one unit of increase of } \log _{10}(\mathrm{CORT}) \text { for } \\
\text { the } 3 \text { colony scenarios (SC) }\end{array}$ & \multirow[t]{3}{*}{2} & \multirow[t]{3}{*}{$\begin{array}{l}\text { Kitaysky et al. (2010), } \\
\text { Satterthwaite et al. } \\
\text { (2012), this study }\end{array}$} \\
\hline $\begin{array}{l}\mathrm{CORT}_{\mathrm{MIN}} \\
\mathrm{CORT}_{\mathrm{MAX}}\end{array}$ & $\begin{array}{c}1.58 \\
19.95\end{array}$ & & $\begin{array}{l}\text { Thresholds for maximum and } \\
\text { minimum productivity }\end{array}$ & & \\
\hline $\begin{array}{l}\bar{C}_{\mathrm{MAX}}\left(\mathrm{Col}_{\mathrm{H}}\right) \\
\bar{C}_{\mathrm{MAX}}\left(\mathrm{Col}_{\mathrm{M}}\right) \\
\bar{C}_{\mathrm{MAX}}\left(\mathrm{Col}_{\mathrm{L}}\right) \\
\bar{C}_{\mathrm{MIN}}\left(\mathrm{Col}_{\mathrm{H}}\right) \\
\bar{C}_{\mathrm{MIN}}\left(\mathrm{Col}_{\mathrm{M}}\right) \\
\bar{C}_{\mathrm{MIN}}\left(\mathrm{Col}_{\mathrm{L}}\right)\end{array}$ & $\begin{array}{c}1 \\
0.6 \\
0.2 \\
0.3 \\
0.2 \\
0.1\end{array}$ & & $\begin{array}{l}\text { Max. and min. average productivity } \\
(\bar{C}) \text { for the } 3 \text { colonies }(\mathrm{H}, \mathrm{M}, \mathrm{L}=\text { high, } \\
\text { medium and low maximum productivity } \\
\text { and sensitivity, respectively). } \sigma= \\
\text { standard deviation }\end{array}$ & & \\
\hline $\begin{array}{l}g_{1}(\mathrm{M}, \mathrm{A}) \\
\mathrm{g}_{1}(\mathrm{~F}, \mathrm{~A}) \\
\mathrm{g}_{2}(\mathrm{M}, \mathrm{A}) \\
\mathrm{g}_{2}(\mathrm{M}, \mathrm{B}) \\
\mathrm{g}_{2}(\mathrm{~F}, \mathrm{~A}) \\
\mathrm{g}_{2}(\mathrm{~F}, \mathrm{~B}) \\
\sigma_{G}\end{array}$ & $\begin{array}{c}20 \\
19 \\
2 \\
1.7 \\
2 \\
1.7 \\
1\end{array}$ & $G$ & $\begin{array}{l}\text { Parameters of the logistic } \\
\text { function for growth }(G) \text { for males }(\mathrm{M}) \text {, } \\
\text { females }(\mathrm{F}), \text { A- and B-chicks (first- } \\
\text { and second-hatched, respectively) } \\
\sigma=\text { standard deviation }\end{array}$ & 4 & $\begin{array}{l}\text { Coulson (2011), } \\
\text { Vincenzi \& Mangel } \\
\text { (2013), Vincenzi et } \\
\text { al. (2013) }\end{array}$ \\
\hline$m_{\mathrm{MAX}}$ & $0.3-0.7$ & \multirow[t]{2}{*}{$m_{\mathrm{PRE}}$} & Max. annual pre-breeding mortality $(m)$ & \multirow[t]{2}{*}{5} & \multirow{2}{*}{$\begin{array}{l}\text { Coulson (2011), } \\
\text { Vincenzi et al. (2013), } \\
\text { this study }\end{array}$} \\
\hline $\begin{array}{l}\beta(\mathrm{M}) \\
\beta(\mathrm{F}) \\
G_{\mathrm{MIN}} \\
G_{\mathrm{MAX}}(\mathrm{M}) \\
G_{\mathrm{MAX}}(\mathrm{F}) \\
m_{\mathrm{MIN}}\end{array}$ & $\begin{array}{c}-1.33 \\
-1.41 \\
7 \\
18 \\
17 \\
0.2\end{array}$ & & $\begin{array}{l}\text { Parameters of the model linking } \\
\text { nestling growth to pre-breeding } \\
\text { mortality for males (M) and females (F) }\end{array}$ & & \\
\hline $\begin{array}{l}I_{\mathrm{MIN}} \\
I_{\mathrm{MAX}}\end{array}$ & $\begin{array}{c}1 \\
5-15\end{array}$ & Immigration & $\begin{array}{l}\text { Min. and max. potential number of adults } \\
(I) \text { immigrating to the colony each year }\end{array}$ & - & This study \\
\hline
\end{tabular}

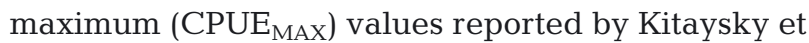
al. (2010). This simulates a scenario in which neither regime shifts nor effects on food of climate change are occurring.

(2) Scenario $A_{\mathrm{F}}$ (auto-correlated): Simulating from an Auto-Regressive Integrated Moving Average (ARIMA) model with only the auto-regressive part of the model $(p)$ and exponential innovations with rate $\rho$. The ARIMA model simulates periods of good food condi- tions followed by periods of poor food conditions and vice versa (i.e. regime shifts);

(3) Scenario $P_{\mathrm{F}}$ (poor): Randomly drawing $\log _{10}$ (CPUE) at each time, $t$, from a uniform distribution bounded by CPUE $\mathrm{MIN}_{\text {and }} \mathrm{CPUE}_{\mathrm{MAX}} / 2$. This scenario simulates years of consistently poor foraging conditions in the proximity of the colony, as may be expected if warm conditions in the Northeastern Pacific persist for the whole simulation time. 


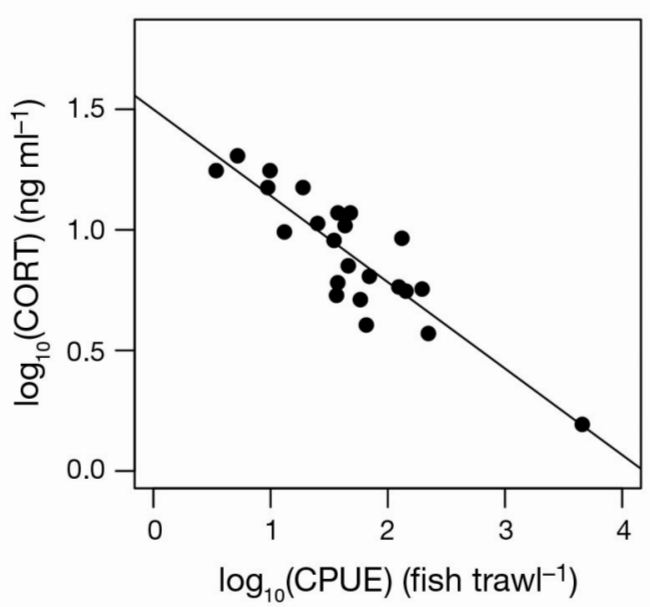

Fig. 2. Linear relationship between mean $\log _{10}(\mathrm{CORT})$ of breeders and $\log _{10}(\mathrm{CPUE})$ (fish trawl ${ }^{-1}$ ) (mean estimate $\pm \mathrm{SE}$ : $\left.\alpha=1.50 \pm 0.07, \beta=-0.36 \pm 0.41 ; p<0.01, R^{2}=0.77\right)$, as found by Kitaysky et al. (2010). We grouped together estimates of food abundance with beach seine and mid-water trawls presented by Kitaysky et al. (2010)

Nutritional stress. Following Kitaysky et al. (2010), we assume that mean $\log _{10}(\mathrm{CORT})$ (where CORT is the concentration of baseline corticosterone in ng $\mathrm{ml}^{-1}$ ) for breeding kittiwakes is linearly related to $\log _{10}(\mathrm{CPUE})$ as:

$\log _{10}(\mathrm{CORT})=\alpha_{\mathrm{CPUE}}+\beta_{\mathrm{CPUE}} \log _{10}(\mathrm{CPUE})+\mathrm{N}\left(0, \sigma_{\mathrm{CPUE}}\right)$

To implement Eq. (1), for each breeding kittiwake, we randomly draw a lognormal deviate from the lognormal distribution $\ln N\left(\mu_{\mathrm{CORT}}, \sigma_{\mathrm{CORT}}\right)$, with $\mu=$ mean

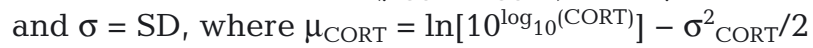
is the location parameter and $\sigma_{\text {CORT }}^{2}=\ln \{[1+$ $\operatorname{Var}($ CORT $\left.)] /\left[\ln \left(10^{\log _{10}(\mathrm{CORT})}\right)\right]^{2}\right\}$ is the scale parameter of the lognormal distribution. We obtained $\operatorname{Var}(\mathrm{CORT})$ from Satterthwaite et al. (2010).

Stress and productivity. The relationship between mean CORT in adults and productivity is likely to be colony-specific (Kitaysky et al. 2010b), since productivity may be limited by factors other than food (such as predation, nest quality, and localized weather conditions), and birds at different colonies (Col) may show different life-history strategies (Schultner et al. 2013).

We determine mean productivity, $\bar{C}$, for the colony given mean $\log _{10}(\mathrm{CORT})$ as obtained from Eq. (1), maximum $\left(\bar{C}_{\mathrm{MAX}}(\mathrm{Col})\right)$ and minimum $\left(\bar{C}_{\mathrm{MIN}}(\mathrm{Col})\right)$ productivity as:

$\begin{cases}\bar{C}=\bar{C}_{\mathrm{MAX}}(\mathrm{Col})+\beta_{\mathrm{SC}}(\mathrm{Col}) \log _{10}\left(\mathrm{CORT} / \mathrm{CORT}_{\mathrm{MIN}}\right) & \text { when } \mathrm{CORT}_{\mathrm{MIN}}<\mathrm{CORT}<\mathrm{CORT}_{\mathrm{MAX}} \\ \bar{C}=\bar{C}_{\mathrm{MAX}}(\mathrm{Col}) & \text { when CORT }<\mathrm{CORT}_{\mathrm{MIN}} \\ \bar{C}=\bar{C}_{\mathrm{MIN}}(\mathrm{Col}) & \text { when CORT }>\mathrm{CORT}_{\mathrm{MAX}}\end{cases}$
Since we investigated North Pacific colonies, we assume that the maximum productivity for a single nest is 2 (i.e. 2 chicks fledging per nest) and use the results of Vincenzi et al. (2013) to model reproduction. We assume that B-chicks mature sooner than A-chicks, and that there are no sex-specific differences in age at recruitment (Vincenzi et al. 2013). More than $90 \%$ of kittiwakes commence breeding between 3 and $8 \mathrm{yr}$ old (Vincenzi et al. 2013). In the IBM, breeders arrive at the colony and form breeding pairs. Although generally adults do not change partners after first breeding (Coulson 2011), it does not change model results if we let adults freely form pairs.

We compute the probability $p(C)$ of a nest producing $C=0,1$, or 2 chicks as follows. First, given $\bar{C}$ from Eq. (2), we randomly draw a variance in productivity $\operatorname{Var}(C)$ for the colony, constraining $\operatorname{Var}(C)$ to be between $\max \left(3 \bar{C}-[\bar{C}]^{2}-2, \bar{C}-[\bar{C}]^{2}\right)$ and $2 \bar{C}-[\bar{C}]^{2}$, since this assures $\min (p(0)), p(1), p(2))>0$. Then, given $\bar{C}$ and $\operatorname{Var}(C)$, we compute $p(i)$, where $i=0,1$, or 2 , by imposing the constraint $\sum_{i=0}^{2} p(i)=1$.

Stress and mortality. Satterthwaite et al. (2010) modeled annual mortality $m(\mathrm{CORT})$ for breeders as:

$$
m(\mathrm{CORT})=\frac{\exp \left(\alpha_{\mathrm{CORT}}+\beta_{\mathrm{CORT}} \mathrm{CORT}\right)}{1+\exp \left(\alpha_{\mathrm{CORT}}+\beta_{\mathrm{CORT}} \mathrm{CORT}\right)}
$$

Setting CORT $=0$, the probability of annual survival for a breeding adult is $\sim 0.92$, while for $\mathrm{CORT}_{\text {MAX }}$ (i.e. when mean colony-wide $\log _{10}$ [CPUE] is at its minimum) the probability of survival is $\sim 0.75$. Annual survival is considered as a return to the colony (i.e. birds not returning may be dead or have permanently emigrated to other colonies).

Sex ratio. There is a small but measureable tendency for pairs in good nutritional condition to produce more male $(\mathrm{M})$ chicks than female $(\mathrm{F})$ chicks (Merkling et al. 2012). The effect is consistent with sex allocation theory, which predicts that with good food conditions there is a biased sex ratio toward the sex, $S$, that has a higher cost to produce and/or has higher expected lifetime reproductive success (Trivers \& Willard 1973). Thus, when mean productivity for year $t$ is higher than the overall mean productivity, we assume that pairs have slightly higher probability of producing males $(\mathrm{p}(S=\mathrm{M})=0.55)$ than females $(\mathrm{p}(S=\mathrm{F})=0.45)$ and vice versa, which is consistent with empirical evidence (Merkling et al. 2012).

Growth. The rate of body growth of chicks, which depends upon social rank and sex (Merkling et al. 2012), is commonly used to examine spatial and temporal effects of changes in food conditions on the 
reproductive performance of seabirds. Male chicks grow significantly faster than females and reach a greater peak mass before fledging (Merkling et al. 2012, Vincenzi \& Mangel 2013). There is evidence of slower growth and lower mass at fledging for younger siblings in kittiwakes (Piatt 2002) and other seabirds (Nisbet et al. 1998), particularly when nutritional conditions are poor (Coulson 2011).

For simplicity, we only model A- and B-chicks, and consider singletons the same as A-chicks. We model mean growth, $G$, during the linear phase of development (Coulson 2011) with a logistic function using data from Vincenzi et al. (2013) and Coulson (2011). The mean growth of chicks of social rank $R$ and sex $S$ in year $t$ when the index of food abundance is $F A_{t}$ is:

$$
G\left(S, R, F A_{t}\right)=\left(g_{1}(S)\left(1-\exp \left(-g_{2}(S, R) F A_{t}\right)\right)\right)
$$

where $F A_{t}$ is the ratio between the $\log _{10}(\mathrm{CPUE})$ in year $t$ and the value representing good foraging conditions $(=2.25$, following Kitaysky et al. 2010). For each chick $i$, we obtain a measure of growth during the linear phase $G_{i}$ by drawing a random deviate from the normal distribution $N\left(G\left(S, R, t, F A_{t}\right), \sigma_{G}\right)$.

Post-fledging and pre-breeding mortality. In kittiwakes, nestling growth rates were found to be positively associated with return to the natal colony and recruitment probability (Coulson 2011). However, in general, the ways that individual traits determine the probability of survival from fledging to breeding in kittiwakes and other seabirds is poorly known (Cam \& Aubry 2011). Cohort effects play a role in local juvenile survival (Kitaysky et al. 2006, Sandvik et al. 2008) and have been mostly associated with climatic vagaries, in particular early in life.

For simplicity, we assume that post-fledging and pre-breeding annual mortality, $m_{\mathrm{PRE}}$, for bird $i$ is only a function of $G_{i}$ and $S_{i}$ maximum and minimum mortality $\left(m_{\mathrm{MAX}}\right.$ and $\left.m_{\mathrm{MIN}}\right)$, and the $G_{\mathrm{MAX}}(S)$ and $G_{\mathrm{MIN}}$ (same for both sexes) corresponding growth $G$ above and below which $m_{\mathrm{PRE}}=m_{\mathrm{MAX}}$ and $m_{\mathrm{PRE}}=m_{\mathrm{MIN}}$, respectively (Coulson 2011, Vincenzi \& Mangel 2013), given by:

$$
\begin{cases}m_{\mathrm{PRE}}=\exp \left(\log \left(m_{\mathrm{MAX}}\right)-\beta(S) \log \left(G_{i} / G_{\mathrm{MIN}}\right)\right) \\ & \text { when } G_{\mathrm{MIN}}<G_{i}<G_{\mathrm{MAX}}(S) \\ m_{\mathrm{PRE}}=m_{\mathrm{MAX}} & \text { when } G_{i}<G_{\mathrm{MIN}} \\ m_{\mathrm{PRE}}=m_{\mathrm{MIN}} & \text { when } G_{i}>G_{\mathrm{MAX}}(S)\end{cases}
$$

Although it is possible (though currently unknown) that the relationship between nestling growth and pre-breeding mortality weakens over time, we maintain the same annual mortality as defined in Eq. (5) so as to implicitly include a measure of quality, in terms of viability, of birds (Cam \& Aubry 2011).

\section{Simulations}

For each of the $\log _{10}$ (CPUE) scenarios described in 'Foraging conditions' above, we simulated and compared the dynamics of 3 colonies with different maximum productivity and sensitivity (or responsiveness) of productivity to an increase in mean CORT of breeding birds over a 50 yr time horizon (Fig. 3). Although maximum productivity and sensitivity to an increase in mean CORT are not necessarily correlated, following the observations of Kitaysky et al. (2010) for Alaskan colonies, we modeled colonies with (1) high maximum productivity and high sensitivity (e.g. Middleton Island) $\left(\mathrm{Col}_{\mathrm{H}}\right),(2)$ medium maximum productivity and medium sensitivity (e.g. Gull Island) ( $\left.\mathrm{Col}_{\mathrm{M}}\right)$, and (3) low maximum productivity and low sensitivity (e.g. Duck Island) $\left(\mathrm{Col}_{\mathrm{L}}\right)$. Thus, for $\mathrm{Col}_{\mathrm{H}}, \bar{C}$ in Eq. (3) decreases steeply with $\log _{10}(\mathrm{CORT})$; for $\mathrm{Col}_{\mathrm{M}}, \bar{C}$ decreases moderately with $\log _{10}(\mathrm{CORT})$, while for $\mathrm{Col}_{\mathrm{L}}, \bar{C}$ is consistently low and fairly insensitive to variations of $\log _{10}$ (CORT) (Fig. 3).

We started each replicate with 250 birds in an equal sex ratio that were born in the colony with ages between 1 and $15 \mathrm{yr}$. Of those 250 birds, approximately 160 (i.e. 80 pairs) were breeders, while the remaining birds were at various pre-breeding stages. We chose 250 birds as initial number for computational reasons, since (1) we did not include densitydependent processes in our model and (2) results did not substantially change with greater numbers of birds. We kept track of mean productivity and number of breeding pairs at each time step, and we considered a colony quasi-extinct when going below 20 pairs (about one-fourth of the initial number of pairs) at any point during simulation time. We ran simulations with alternative values of $m_{\mathrm{MAX}}$ to test whether growth-dependent pre-breeding survival is likely to substantially influence colony dynamics and risk of quasi-extinction. Finally, we checked whether an annual immigration of a number $I$ of sexually mature birds from other colonies, randomly drawn from $U\left(I_{\mathrm{MIN}}, I_{\mathrm{MAX}}\right)$ and of age between 3 and 7 , may have a role in maintaining failing colonies. To do so, we ran 100 replicates for every combination of colony type Col, scenarios of temporal succession of $\log _{10}$ (CPUE) $\left(R_{\mathrm{F}}, A_{\mathrm{F}}, P_{\mathrm{F}}\right)$, and values of $I_{\mathrm{MAX}}$ and $m_{\mathrm{MAX}}$ (Table 1$)$. Within the 100 replicates, we used 10 different series of food abundance by fixing the seed value for the pseudo-random number generator. 


\section{Statistical analysis of simulation results}

We analyzed the results of simulations using standard statistical methods, treating simulation output as pseudo-empirical data. We fitted linear and generalized linear models (with logit link function) using as response variables the median number of breeding pairs over the simulation time and quasi-extinction risk, respectively. As predictors, we used Col, $I_{\mathrm{MAX}}, m_{\mathrm{MAX}}$, and we fitted separate models for each scenario of temporal succession of food abundance. When food abundance was temporally autocorrelated, we also included as predictor a dummy categorical variable $(Z)$ for the seed of the pseudo-random number generator determining the temporal succession of $\log _{10}$ (CPUE). We did not include interactions among predictors in the models. Although we report p-values, our considerations on the relative importance of the various predictors are not based on statistical significance, but rather on effect sizes (cf. White et al. 2014). We logtransformed median colony size as a response variable. For models of median colony size, we present and discuss semi-partial correlation coefficients, which represent the specific portion of variance in median colony size explained by a given predictor in the multiple linear regression model. Code and data to reproduce the analyses are available at http://dx.doi.org/10.6084/m9.figshare. 1012892.

\section{RESULTS}

\section{Colony size over time}

Different scenarios of colony-wide productivity lead to considerable differences in colony dynamics (Fig. 4), as well as how and if colonies are able to recover when, after years of declining colony size due to the effects of nutritional stress, there is an improvement in foraging conditions. In the scenario with no strong immigration, $\mathrm{Col}_{\mathrm{H}}$ (colony with high maximum productivity and high sensitivity to nutritional stress) responded quickly in terms of colony size to an increase in productivity after years of high nutritional stress with either low or high mortality of pre-breeders. On the contrary, $\mathrm{Col}_{\mathrm{M}}$ (colony with medium maximum productivity and medium sensitivity to stress) showed a good increase in colony size after years of bad conditions only when the mortality of pre-breeders was low. Colony size of $\mathrm{Col}_{\mathrm{L}}$ (colony with low maximum productivity and low sensitivity

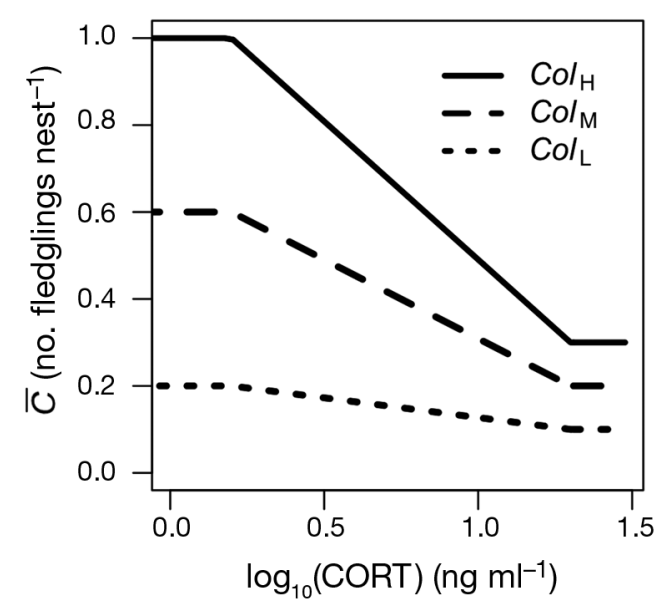

Fig. 3. Sensitivity of productivity $(\bar{C})$ to an increase in mean $\log _{10}(\mathrm{CORT})$ for colonies with high $\left(\mathrm{Col}_{\mathrm{H}}\right)$, medium $\left(\mathrm{Col}_{\mathrm{M}}\right)$ and low $\left(\mathrm{Col}_{\mathrm{L}}\right)$ sensitivities (as well as maximum productivity). $\mathrm{Col}_{\mathrm{L}}$ may represent Duck Island kittiwake colony, $\mathrm{Col}_{\mathrm{M}}$ Gull Island and $\mathrm{Col}_{\mathrm{H}}$ Middleton Island

to stress) was constantly low in absence of strong immigration, even when mortality of pre-breeders was at its lowest (i.e. annual probability of dying = $0.3)$.

\section{Statistical analysis of simulation results}

We observed considerable differences in the risk of quasi-extinction among colonies (Fig. 5) with an important role played by the potential number of immigrants and by year-to-year variation in food abundance. For all colonies, the risk of quasi-extinction decreased with an increase in potential immigrants. The maximum risk of quasi-extinction for all colonies was clearly observed in scenario $P_{\mathrm{F}}$ (i.e. when food abundance was consistently poor). On the other hand, when food conditions were not consistently poor (i.e. scenarios $A_{\mathrm{F}}$ and $R_{\mathrm{F}}$ ), immigration of up to 5 breeders a year greatly reduced $\left(\mathrm{Col}_{\mathrm{L}}\right)$ or almost always avoided $\left(\mathrm{Col}_{\mathrm{H}}, \mathrm{Col}_{\mathrm{M}}\right)$ quasi-extinction (Fig. 5). With equal potential number of immigrants, the risk of quasi-extinction was lower in scenario $R_{\mathrm{F}}$ than when it was temporally auto-correlated (scenario $A_{\mathrm{F}}$ ) (Fig. 5, Table 2).

Maximum mortality for pre-breeders had a very small influence on the median number of breeding pairs, while colony type was the most important determinant of the median number of pairs in scenarios $A_{\mathrm{F}}$ and $R_{\mathrm{F}}$ (Table 2). Potential immigration was unimportant in scenarios $A_{\mathrm{F}}$ and $R_{\mathrm{F}}$ (Table 2). However, in scenario $P_{\mathrm{F}}$, the potential number of immi- 


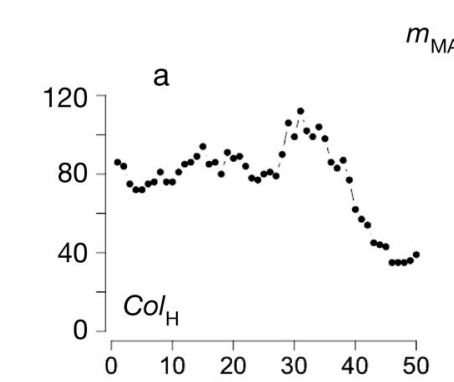

$m_{\mathrm{MAX}}=0.3$
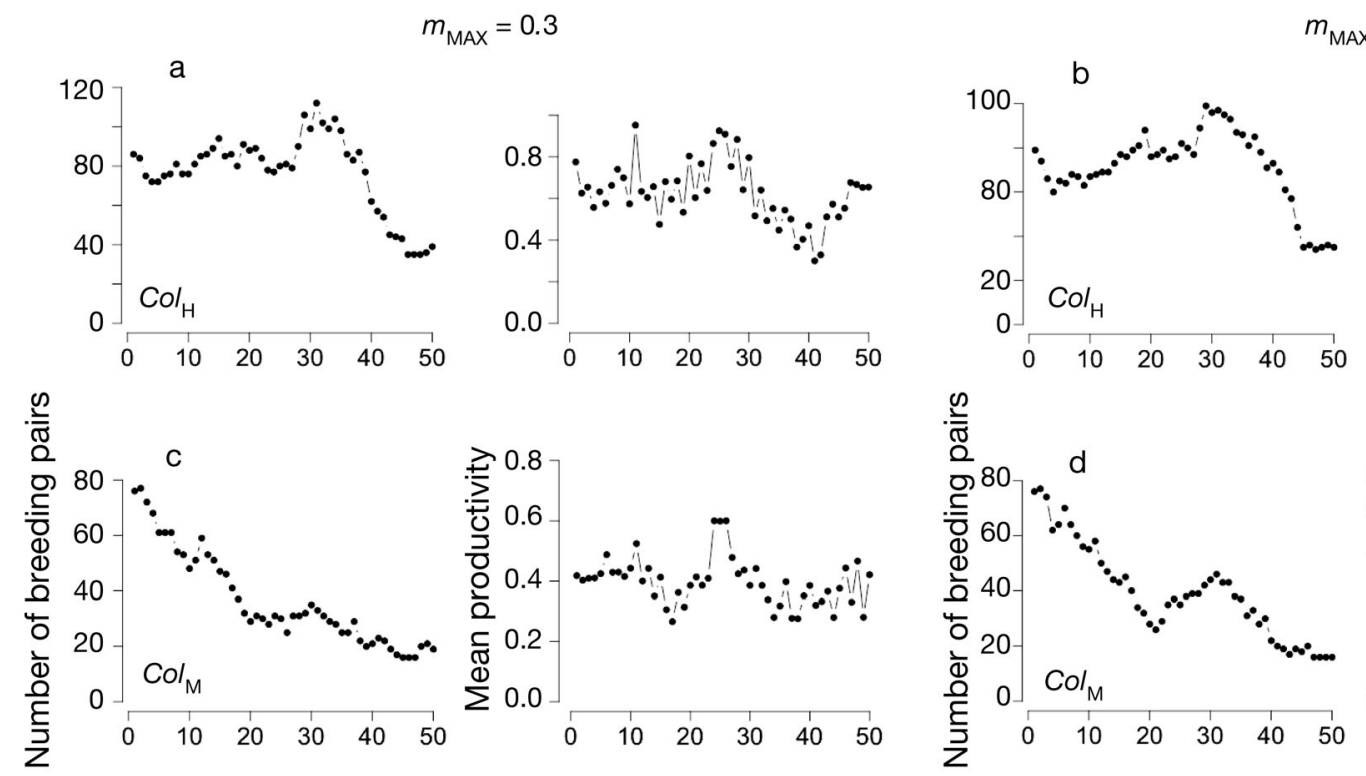

$m_{\text {MAX }}=0.5$
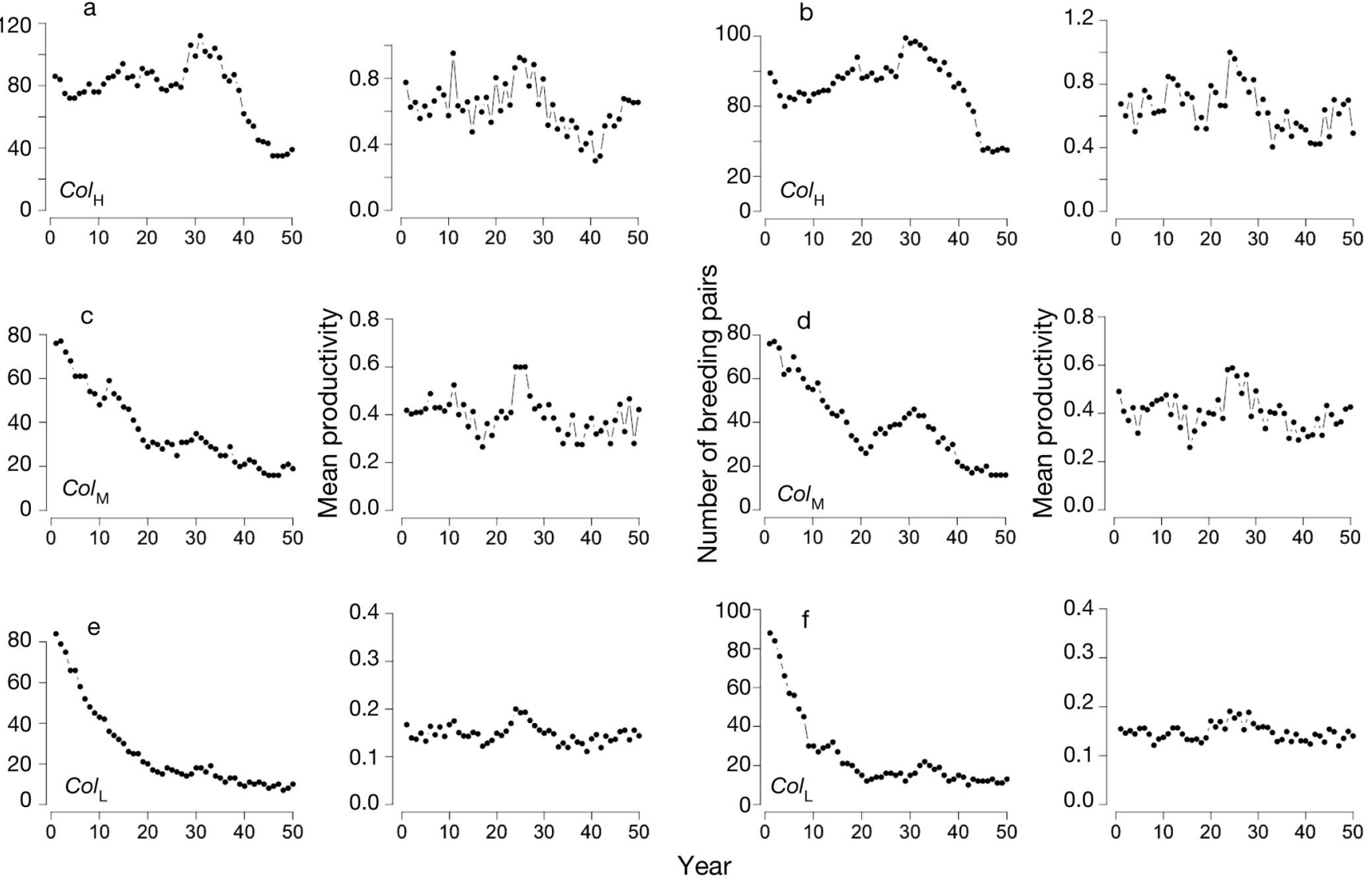

Fig. 4. Representative examples of simulations with auto-correlated $\log _{10}(\mathrm{CPUE})$ for maximum pre-breeding mortality, $m_{\mathrm{MAX}}$ of 0.3 (left column) or 0.5 (right column) for kittiwake colonies with $(\mathrm{a}, \mathrm{b})$ high $\left(\mathrm{Col}_{\mathrm{H}}\right)$, $(\mathrm{c}, \mathrm{d})$ medium $\left(\mathrm{Col}_{\mathrm{M}}\right)$ or $(\mathrm{e}, \mathrm{f})$ low $\left(\mathrm{Col}_{\mathrm{L}}\right)$ sensitivities to an increase in mean colony-wide $\log _{10}(\mathrm{CORT})$. Maximum number of birds migrating each year to the colonies was 5. For all 6 replicates we used the same sequence of $\log _{10}$ (CPUE), although mean colony-wide productivity may change due to stochasticity. For each replicate, we report number of breeding pairs for each year and mean colony-wide productivity

grants was the most important determinant of median number of breeding pairs (Table 2). In addition, in scenario $P_{\mathrm{F}}$, all colonies showed a very low median number of breeding pairs and little variability in median colony size (Fig. 6). For each colony, we observed the highest variability in scenario $A_{\mathrm{F}}$. The temporal succession of food abundance (i.e. dummy variable $Z$ ) when simulating from the ARIMA model was moderately important for median number of breeding pairs (Table 2).

\section{DISCUSSION}

Understanding how climate change will affect species requires an approach linking behavior, physiology, and population dynamics in a consistent and testable framework. In long-lived species, since no single study is likely to provide the inclusive information on the intrinsic and extrinsic factors influencing colony-level dynamics, we must bring together information from different studies. Modeling as we have done here provides the balance between complexity and fidelity to nature, and meaningful interpretation of results.

Our results show that colony size and dynamics, and the risk of quasi-extinction are sensitive to how nutritional stress (which is linked to foraging conditions in the proximity of the colony) of breeding birds translates into productivity and survival. In this regard, our work complements that of Wolf \& Mangel (2008) on the Steller sea lion Eumetopias jubatus in the Bering Sea, in which the decline of modeled populations was related to both abundance and quality 

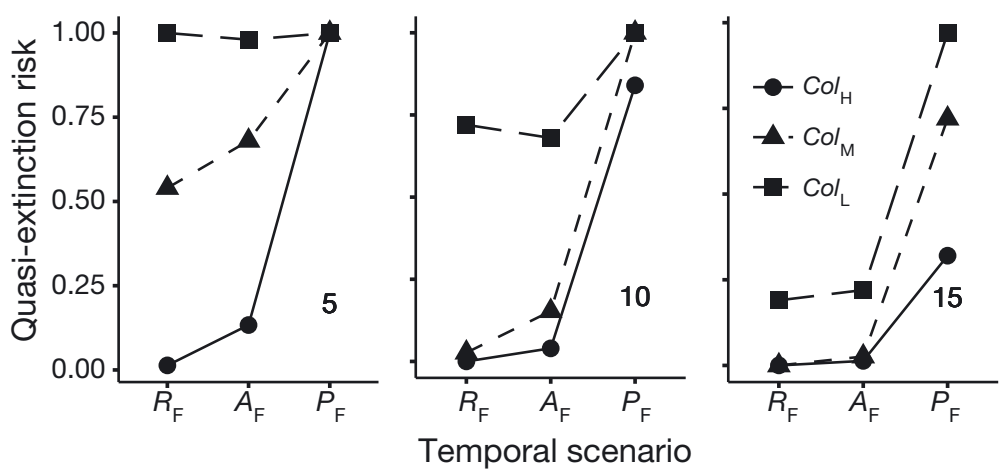

Fig. 5. Quasi-extinction risk in colonies with high $\left(\mathrm{Col}_{\mathrm{H}}\right)$, medium $\left(\mathrm{Col}_{\mathrm{M}}\right)$ and low $\left(\mathrm{Col}_{\mathrm{L}}\right)$ sensitivity of productivity to increase in mean $\log _{10}(\mathrm{CORT})$. In $R_{\mathrm{F}}$, food abundance is randomly drawn each year from U(CPUE $\mathrm{MIN}_{\text {, }}$ CPUE ${ }_{\mathrm{MAX}}$ ), in $P_{\mathrm{F}}$, food abundance is randomly drawn each year from $U\left(\right.$ CPUE $\left._{\mathrm{MIN}}, \mathrm{CPUE}_{\mathrm{MAX}} / 2\right)$, while in $A_{\mathrm{F}}$, food abundance through time is simulated with an Auto-Regressive Integrated Moving Average (ARIMA) model with exponential innovations. From left to right, panels are for increasing potential number of birds migrating to the colonies (i.e. 5, 10, 15)

\section{Food abundance}

Satterthwaite et al. (2012) found that local factors rather than large-scale climate variability likely determine variation in the number of fledglings per nest in several Northeastern Pacific colonies of kittiwakes. In the Northeastern Pacific, especially after the regime shift around 1977, kittiwake colonies have often been food-limited, with severe food deprivation leading to several reproductive failures (Piatt \& Harding 2007). Warmer conditions since the late 1970s favored demersal species such as pollock Theragra chalcogramma and halibut Hippoglossus stenolepis, along with other species of lesser importance for kittiwakes (e.g. salmon Onchorynchus gorboscha and $O$. keta). Capelin re-emerged between 2000 and 2003 and after 2008 as the predominant forage species, due to a return to cooler oceanographic conditions. Kittiwakes at Middleton Island responded favorably to the return of capelin by rapidly shifting diet and producing substantially higher number of nests (Hatch 2013).

Table 2. Statistical analyses of simulation results when the response variable is median colony size (ordinary least-square regression, OLS) or quasi-extinction (logistic regression, GLM with logit link function). Colony scenarios $\mathrm{Col}_{\mathrm{H}}, \mathrm{Col}_{\mathrm{M}}$, and $\mathrm{Col}_{\mathrm{L}}$ are described in Fig. 3. $m_{\mathrm{MAX}}$ is maximum annual mortality of pre-breeders with slow growth, $I_{\mathrm{MAX}}$ is the maximum number of birds immigrating from other colonies each year and $Z_{i}$ (where $i=1 \ldots 10$ ) is a dummy variable representing the temporal succession of food abundance (included only for the auto-correlated scenario). Median colony size as a response variable in the OLS model was log-transformed. $\mathrm{sr}=$ semi-partial regression coefficients for median population size; $N^{\prime} \mathrm{s} \mathrm{R}^{2}=\mathrm{Nagelkerke's}$ $\mathrm{R}^{2}$; bracketed values $=\mathrm{SD}$. All $\mathrm{p}<0.01$, except where marked with the symbol ${ }^{\wedge}$, for which $\mathrm{p}>0.05$. In $R_{\mathrm{F}}$, food abundance is randomly drawn each year from $U\left(\mathrm{CPUE}_{\mathrm{MIN}} \mathrm{CPUE}_{\mathrm{MAX}}\right)$, in $P_{\mathrm{F}}$, food abundance is randomly drawn each year from $U\left(\mathrm{CPUE}_{\mathrm{MIN}}, \mathrm{CPUE}_{\mathrm{MAX}} / 2\right)$, while in $A_{\mathrm{F}}$, food abundance through time is simulated with an Auto-Regressive Integrated Moving Average (ARIMA) model with exponential innovations. na: not available

\begin{tabular}{|c|c|c|c|c|c|c|c|c|c|}
\hline \multirow{4}{*}{ Predictor } & \multicolumn{9}{|c|}{ Response variable } \\
\hline & \multirow{2}{*}{\multicolumn{3}{|c|}{$\begin{array}{c}\text { Quasi-extinction } \\
R_{\mathrm{F}}\end{array} A_{\mathrm{F}} \quad P_{\mathrm{F}}$}} & \multicolumn{4}{|c|}{-Median population size- } & \multirow{2}{*}{\multicolumn{2}{|c|}{$P_{\mathrm{F}}$}} \\
\hline & & & & $R_{\mathrm{F}}-$ & 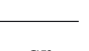 & $-A_{\mathrm{F}}-$ & & & \\
\hline & & & & $\mathrm{R}^{2}=0.88$ & $\mathrm{sr}$ & $\mathrm{R}^{2}=0.87$ & $\mathrm{sr}$ & $\mathrm{R}^{2}=0.91$ & $\mathrm{sr}$ \\
\hline Intercept & $-2.44(0.81)$ & $1.50(0.60)$ & $6.08(0.70)$ & $3.88(0.02)$ & na & $3.59(0.03)$ & na & $2.50(0.02)$ & na \\
\hline $\mathrm{Col}_{\mathrm{M}}$ & $4.47(0.73)$ & $4.51(0.43)$ & $2.20(0.26)$ & $-0.55(0.01)$ & 0.68 & $-0.47(0.01)$ & 0.46 & $-0.24(0.01)$ & 0.17 \\
\hline $\mathrm{Col}_{\mathrm{L}}$ & $8.80(0.78)$ & $9.29(0.65)$ & $4.66(0.50)$ & $-1.13(0.01)$ & na & $-1.02(0.01)$ & na & $-0.46(0.01)$ & na \\
\hline$m_{\mathrm{MAX}}$ & $2.20(0.65)$ & $1.90(0.73)$ & $4.64(0.75)$ & $-0.18(0.03)$ & 0.002 & $-0.22(0.03)$ & 0.003 & $-0.39(0.03)$ & 0.02 \\
\hline$I_{\mathrm{MAX}}$ & $-0.61(0.04)$ & $-0.85(0.06)$ & $-0.62(0.05)$ & $0.06(0.001)$ & 0.20 & $0.065(0.001)$ & 0.19 & $0.09(0.001)$ & 0.68 \\
\hline$Z_{2}$ & na & $0.95(0.52)^{\wedge}$ & na & na & na & $0.23(0.02)$ & 0.26 & na & na \\
\hline$Z_{3}$ & na & $0.11(0.49)^{\wedge}$ & na & na & na & $-0.04(0.02)^{\wedge}$ & na & na & na \\
\hline$Z_{4}$ & na & $0.11(0.49)^{\wedge}$ & na & na & na & $0.009(0.02)^{\wedge}$ & na & na & na \\
\hline$Z_{5}$ & na & $5.15(0.59)$ & na & na & na & $-0.33(0.02)$ & na & na & na \\
\hline$Z_{6}$ & na & $-2.60(0.54)$ & na & na & na & $0.13(0.02)$ & na & na & na \\
\hline$Z_{7}$ & na & $-3.37(0.56)$ & na & na & na & $0.34(0.02)$ & na & na & na \\
\hline$Z_{8}$ & na & $-6.41(0.78)$ & na & na & na & $0.78(0.02)$ & na & na & na \\
\hline$Z_{9}$ & na & $-4.45(0.62)$ & na & na & na & $0.57(0.02)$ & na & na & na \\
\hline$Z_{10}$ & na & $-0.80(0.52)^{\wedge}$ & na & na & na & $-0.04(0.02)^{\wedge}$ & na & na & na \\
\hline
\end{tabular}



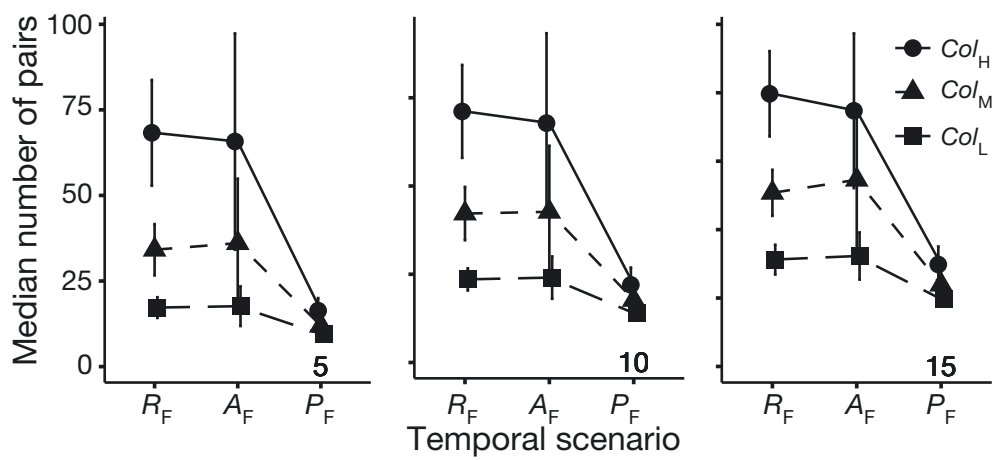

Fig. 6. Mean across replicates of the median number of breeding pairs over the simulation time in each replicate (vertical bars show the standard deviation) in colonies with high $\left(\mathrm{Col}_{\mathrm{H}}\right)$, medium $\left(\mathrm{Col}_{\mathrm{M}}\right)$ and low $\left(\mathrm{Col}_{\mathrm{L}}\right)$ sensitivity of productivity to an increase in mean $\log _{10}$ (CORT). In $R_{\mathrm{F}}$ (random), food abundance is randomly drawn each year from $U\left(\mathrm{CPUE}_{\mathrm{MIN}}, \mathrm{CPUE}_{\mathrm{MAX}}\right)$, in $P_{\mathrm{F}}$ (poor) food abundance is randomly drawn each year from $U\left(\mathrm{CPUE}_{\mathrm{MIN}}, \mathrm{CPUE}_{\mathrm{MAX}} / 2\right)$, while in $A_{\mathrm{F}}$ (auto-correlated) food abundance through time is simulated with an Auto-Regressive Integrated Moving Average (ARIMA) model with exponential innovations. From left to right, panels are for increasing potential number of birds migrating to the colonies (i.e. $5,10,15)$

To date, for Pacific colonies the relationships between productivity and typical environmental indices (Pacific Decadal Oscillation, Winter Ice Cover and summer Sea Surface Temperature, SST) have been found to be weak (Satterthwaite et al. 2012). However, SST in the spring at year $t-1$ was correlated with kittiwake colony productivity at year $t$ in the Atlantic Ocean (Frederiksen et al. 2007), where kittiwakes prey primarily on age-1 sandeel, Ammodytes $\mathrm{sp}$. The delayed effect of SST on breeding productivity reflects the availability of sandeel, whose abundance was strongly determined by water temperature at the time of hatching. However, a remaining puzzle is understanding how the regime shifts in the Northeastern Pacific of the late 1970s and the associated change in food drove colony declines in the Bering Sea (Springer 1998, Hunt et al. 2002, Byrd et al. 2008a), while other colonies in the Aleutian Archipelago increased in size (Byrd et al. 2005). Depending on oceanographic conditions and the physical environment surrounding the colony (e.g. shelf break and ice cover) some colonies may be 'sinks' or at least depend on 'source' colonies (Byrd et al. 2008a), and changing oceanographic conditions may reverse the roles from 'sink' to 'source' and vice versa.

Region-specific oceanographic conditions are likely to be important for kittiwake colony dynamics. That is, as with Steller sea lions (Wolf \& Mangel 2008), understanding colony dynamics in the Northeastern Pacific Ocean requires studies at smaller spatial scales than the Bering Sea or Gulf of Alaska. For example, demographic parameters (e.g. breeding success) vary most between colonies and much less within colonies (Frederiksen et al. 2005, Byrd et al. 2008a,b). Piatt \& Harding (2007) suggested that distinct and persistent oceanographic regimes in the proximity of colonies determine the availability of forage fish to kittiwakes within those areas.

Regime shifts imply that multiple years of poor food conditions tend to be followed by multiple years of good food conditions (i.e. as represented in our scenario with temporally auto-correlated food abundance). For that scenario, the specific time series of food abundance was one of the main determinants of the median colony size and risk of quasiextinction. This has a profound implication for empirical studies, since the effects of regime shifts are likely to be colony-specific, and data on food quality, quantity, and availability have to be collected locally. With non-systematic trawl surveys, missing years are often filled in by statistical methods with a priori assumptions about the auto-correlation structure. However, such trawl surveys do not allow insights into the nature of that auto-correlation.

\section{Trade-off between reproduction and survival}

Our results showed that maximum colony-wide productivity and the sensitivity of colony-wide productivity to variation in the mean stress of breeding birds are critical for colony dynamics. Although we cannot exclude that differences among colonies in the relationship between nutritional stress and productivity may be caused by factors other than prevalent life-history strategies (e.g. predation, nest quality, local weather conditions), the different lifehistory strategies may emerge as phenotypically plastic adaptations to foraging conditions, in particular those experienced early in life.

For kittiwakes living in Pacific colonies, we have very little information on how basic vital traits and life histories (e.g. annual adult survival and age at recruitment) change over time and space. Thus, we did not include a trade-off between survival and reproductive success (or productivity) at the colony level, although life-history theory predicts such a trade-off. Kitaysky et al. (2010) found that despite 
incurring comparable nutritional stress levels, kittiwakes at Gull Island successfully reproduced, while kittiwakes at Duck Island failed or skipped breeding, which probably translated into higher adult survival at Duck Island (Piatt \& Harding 2007). However, in other simulations, we found that increasing adult survival when less energy is allocated to reproduction is insufficient to avoid a very high risk of quasiextinction if productivity is consistently poor over time.

\section{Immigration}

Occasional recruitment and/or immigration may be important in the initiation, growth and maintenance of some small to medium-sized colonies. Since some kittiwake colonies in the Northeastern Pacific are organized into larger meta-populations, our model may be seen as a simplification of spatially structured dynamics (Kildaw et al. 2008). Coulson (2011) argued that each North Atlantic kittiwake colony is able to attract new birds from a pool of pre-breeders produced in other colonies within approximately $1000 \mathrm{~km}$. We found that when food abundance is not consistently poor over time, a few kittiwakes immigrating from other colonies each year substantially reduces the risk of quasi-extinction of colonies with consistent low productivity. The determinants of immigration to a colony different from the one in which the bird grew as chick or recruited are most likely contextdependent (Boulinier \& Danchin 1997). Two of the potential mechanisms are (1) the habitat quality hypothesis (birds are looking for a higher-quality habitat) and (2) the individual quality hypothesis (lower-quality birds expect to increase their fitness by moving to a less established colony) (Kildaw et al. 2005). The 2 hypotheses on the determinants of immigration to colonies different from the natal one are expected to have different effects on meta-population dynamics. In the case of (1), declining colonies due to poor nesting habitat or consistently poor foraging conditions in the proximity of the colony may fail to attract kittiwakes emigrating from other colonies, while in the case of (2), lower-quality kittiwakes may still be emigrating to a declining colony, but whether they will be reproductively successful (and thus contribute to the rescue of the failing colony) may also be in this case context-dependent. In fact, a stronger correlation between individual quality and fitness is expected in harsher environments or when competition for limited resources is stronger (Leung \& Forbes 1997, Reed et al. 2007); thus, lower-quality birds may fail to reproduce if the same limiting factors that caused the emigration from the natal colony persist in the colony to which they immigrate. On the other hand, if the new colony provides more favorable conditions than the natal one (e.g. weaker competition due to lower density), lower-quality individuals may survive up to sexual maturity, reproduce successfully, and help failing colonies persist.

\section{Growth during the nestling phase}

Our results showed that variation in nestling growth-dependent survival of pre-breeders is unlikely to be important for kittiwake colony dynamics, but it is unknown whether poor growth as a result of food stress has effects on survival and reproductive performance of birds when they enter their adult phase. If this is the case, poor growth will impact the survival of breeders and productivity, the most important cause of colony decline. However, after taking into account sex and social rank, mean growth of kittiwake chicks tends to be positively correlated with mean productivity at the colony level (Vincenzi et al. 2013). This result suggests that in case of poor food conditions, only chicks of high intrinsic quality are able to fledge, and their reproductive performance should not dramatically be affected by the poorer conditions during the nestling phase.

\section{Food supplementation as a measure to increase productivity}

Our results also show that without a contribution of breeders from other colonies, those with consistently low productivity cannot persist. At Middleton Island, a unique long-term feeding experiment showed that food supplementation during breeding significantly increased both reproductive productivity and chick growth (Gill et al. 2002). Food supplementation often yields almost immediate increases in productivity (Robb et al. 2008), although food supplementation may also have short-term delayed negative effects (e.g. the recruitment of low-quality individuals) (Plummer et al. 2013). Although largescale feeding might not be feasible either logistically or financially, food supplementation might be among the few conservation measures to help a colony persist when facing a strong decline in productivity. 


\section{Testing model results on empirical data}

While it would be ideal to test the predictions of this model on data that were not used to estimate parameters, it cannot be done at the current time. No joint information on year-varying vital rates and abundance data is available for any of the Pacific kittiwake colonies. The colony of Middleton Island (Alaska) has been monitored since the early 1990s, but only a limited number of chicks have recruited as breeders since the start of the monitoring program (Vincenzi et al. 2013) and none of the banded breeders have yet reached the maximum life span for kittiwakes ( 25 yr). Therefore, both apparent survival of pre-breeders and breeders have yet to be estimated. In addition, due to financial constraints, only one CPUE-year of data has been collected for the Middleton colony (Kitaysky et al. 2010). Thus, as good theory should do, our work will help guide future empirical work.

In our model, food availability in the proximity of the colony is the most important driver of population dynamics (along with responsiveness of the colony to stress), and it generates covariances among vital rates of a cohort. For instance, poor food conditions in a year reduce productivity, reduce growth of chicks and increase mortality of the same cohort during the pre-breeding stage. While at present we lack joint estimations of vital rates, there is ample evidence for Pacific kittiwakes that poorer food conditions decrease productivity (Gill et al. 2002), reduce growth rates of chicks (Vincenzi et al. 2013), and affect age at recruitment of the same cohort (Vincenzi et al. 2013). Based on our model results, we suggest further investigation of the relationship between environmental indices and productivity, the auto-correlation structure of food abundance at different spatial scales, and of the differences among colonies in the sensitivity of productivity to variations in nutritional stress.

Acknowledgements. This work was supported by funding from the North Pacific Research Board (BEST-BSIERP project B74) and by the Center for Stock Assessment Research (CSTAR), a partnership between the Fisheries Ecology Division, NOAA Fisheries, Santa Cruz, and the University of California Santa Cruz. S.V. was supported by an IOF Marie Curie Fellowship FP7-PEOPLE-2011-IOF for the project 'RAPIDEVO' on rapid evolutionary responses to climate change in natural populations.

\section{LITERATURE CITED}

Anderson PJ, Piatt JF (1999) Community reorganization in the Gulf of Alaska following ocean climate regime shift. Mar Ecol Prog Ser 189:117-123
Benoit-Bird K, Kuletz K, Heppell S, Jones N, Hoover B (2011) Active acoustic examination of the diving behavior of murres foraging on patchy prey. Mar Ecol Prog Ser 443:217-235

> Boulinier T, Danchin E (1997) The use of conspecific reproductive success for breeding patch selection in terrestrial migratory species. Evol Ecol 11:505-517

- Byrd GV, Renner HM, Renner M (2005) Distribution patterns and population trends of breeding seabirds in the Aleutian Islands. Fish Oceanogr 14:139-159

Byrd GV, Schmutz JA, Renner HM (2008a) Contrasting population trends of piscivorous seabirds in the Pribilof Islands: a 30-year perspective. Deep-Sea Res II 55: 1846-1855

Byrd GV, Sydeman WJ, Renner HM, Minobe S (2008b) Responses of piscivorous seabirds at the Pribilof Islands to ocean climate. Deep-Sea Res II 55:1856-1867

Cam E, Aubry L (2011) Early development, recruitment and life history trajectory in long-lived birds. J Ornithol 152: 187-201

Ciannelli L, Bailey KM, Chan KS, Belgrano A, Stenseth NC (2005) Climate change causing phase transitions of walleye pollock (Theragra chalcogramma) recruitment dynamics. Proc R Soc B 272:1735-1743

Coulson JC (2011) The kittiwake. T \& AD Poyser, London

Coyle KO, Eisner LB, Mueter FJ, Pinchuk AI and others (2011) Climate change in the southeastern Bering Sea: impacts on pollock stocks and implications for the oscillating control hypothesis. Fish Oceanogr 20:139-156

> Frederiksen M, Harris MP, Wanless S (2005) Inter-population variation in demographic parameters: a neglected subject? Oikos 111:209-214

> Frederiksen M, Edwards M, Mavor R, Wanless S (2007) Regional and annual variation in black-legged kittiwake breeding productivity is related to sea surface temperature. Mar Ecol Prog Ser 350:137-143

Gill VA, Hatch SA (2002) Components of productivity in black-legged kittiwakes Rissa tridactyla: response to supplemental feeding. J Avian Biol 33:113-126

Gill VA, Hatch SA, Lanctot RB (2002) Sensitivity of breeding parameters to food supply in black-legged kittiwakes Rissa tridactyla. Ibis 144:268-283

Grimm V, Railsback SF (2005) Individual-based modeling and ecology. Princeton University Press, Princeton, NJ

Hare SR, Mantua NJ (2000) Empirical evidence for North Pacific regime shifts in 1977 and 1989. Prog Oceanogr 47: 103-145

> Hatch SA (2013) Kittiwake diets and chick production signal a 2008 regime shift in the Northeast Pacific. Mar Ecol Prog Ser 477:271-284

Hunt GL Jr, Stabeno PJ, Walters G, Sinclair E, Brodeur RD, Napp JM, Bond NA (2002) Climate change and control of the southeastern Bering Sea pelagic ecosystem. DeepSea Res II 49:5821-5853

> Hunt GL Jr, Stabeno PJ, Strom S, Napp JM (2008) Patterns of spatial and temporal variation in the marine ecosystem of the southeastern Bering Sea, with special reference to the Pribilof Domain. Deep-Sea Res II 55:1919-1944

> Jenouvrier S, Caswell H, Barbraud C, Holland M, Stroeve J, Weimerskirch H (2009) Demographic models and IPCC climate projections predict the decline of an emperor penguin population. Proc Natl Acad Sci USA 106: 1844-1847

Jodice PGR, Roby DD, Turco KR, Suryan RM and others (2006) Assessing the nutritional stress hypothesis: rela- 
tive influence of diet quantity and quality on seabird productivity. Mar Ecol Prog Ser 325:267-279

Kildaw SD, Irons DB, Nyesewander DR, Buck CL (2005) Formation and growth of new seabird colonies: the significance of habitat quality. Mar Ornithol 33:49-58

Kildaw D, Irons DB, Buck CL (2008) Habitat quality and metapopulation dynamics of black-legged kittiwakes Rissa tridactyla. Mar Ornithol 45:35-45

Kitaysky AS, Hunt GL Jr, Flint EN, Rubega MA, Decker MB (2000) Resource allocation in breeding seabirds: responses to fluctuations in their food supply. Mar Ecol Prog Ser 206:283-296

Kitaysky AS, Kitaiskaia EV, Piatt JF, Wingfield JC (2006) A mechanistic link between chick diet and decline in seabirds? Proc R Soc B 273:445-450

Kitaysky AS, Piatt J, Hatch SA, Kitaiskaia EV, BenowitzFredericks ZM, Shultz MT, Wingfield JC (2010) Food availability and population processes: severity of nutritional stress during reproduction predicts survival of long-lived seabirds. Funct Ecol 24:625-637

Leung B, Forbes MR (1997) Modeling fluctuating asymmetry in relation to stress and fitness. Oikos 78:397-405

- Merkling T, Leclaire S, Danchin E, Lhuillier E and others (2012) Food availability and offspring sex in a monogamous seabird: insights from an experimental approach. Behav Ecol 23:751-758

Mueter FJ, Litzow MA (2008) Sea ice retreat alters the biogeography of the Bering Sea continental shelf. Ecol Appl 18:309-320

Nisbet ICT, Spendelow JA, Hatfield JS, Zingo JM, Gough GA (1998) Variation in growth of roseate tern chicks. II. Early growth as an index of parental quality. Condor 100: 305-315

Piatt JF (2002) Response of seabirds to fluctuations in forage fish density. Final report to Exxon Valdez Oil Spill Trustee Council (Restoration Project 00163M) and Mineral Management Service (Alaska OCS Region). Alaska Science Center, US Geological Survey, Anchorage, AK

Piatt JF, Harding AMA (2007) Population ecology of seabirds in Cook Inlet. In: Spies R (ed) Long-term ecological change in the northern Gulf of Alaska. Elsevier, Amsterdam, p 335-352

Plummer KE, Bearhop S, Leech DI, Chamberlain DE, Blount JD (2013) Winter food provisioning reduces future breeding performance in a wild bird. Sci Rep 3:2002

Reed DH, Nicholas AC, Stratton GE (2007) Genetic quality of individuals impacts population dynamics. Anim Conserv 10:275-283

Robb GN, McDonald RA, Chamberlain DE, Bearhop S (2008) Food for thought: supplementary feeding as a driver of ecological change in avian populations. Front Ecol Environ 6:476-484

Editorial responsibility: Jacob González-Solís, Barcelona, Spain
Sandvik H, Erikstad KE, Fauchald P, Tveraa T (2008) High survival of immatures in a long-lived seabird: insights from a long-term study of the Atlantic puffin (Fratercula arctica). Auk 125:723-730

Satterthwaite WH, Kitaysky AS, Hatch SA, Piatt JF, Mangel M (2010) Unifying quantitative life-history theory and field endocrinology to assess prudent parenthood in a long-lived seabird. Evol Ecol Res 12:779-792

Satterthwaite WH, Kitaysky AS, Mangel M (2012) Linking climate variability, productivity and stress to demography in a long-lived seabird. Mar Ecol Prog Ser 454: 221-235

Schultner J, Kitaysky AS, Gabrielsen GW, Hatch SA, Bech C (2013) Differential reproductive responses to stress reveal the role of life-history strategies within a species. Proc R Soc B 280:20132090, doi: 10.1098/rspb.2013.2090

Springer AM (1998) Is it all climate change? Why marine bird and mammal populations fluctuate in the North Pacific. In: Holloway G, Muller P, Henderson D (eds) Proceedings of the 10th 'Aha Huliko': a Hawaiian winter workshop on biotic impacts of extratropical climate variability in the Pacific, 26-30 January 1998. SOEST Spec Pub, Honolulu, p 109-119

Suryan RM (2000) Foraging ecology, reproductive biology, and population dynamics of black-legged kittiwakes (Rissa tridactyla) in Prince William Sound, Alaska. In: Duffy DC (ed) APEX project: Alaska predator ecosystem experiment in Prince William Sound and the Gulf of Alaska. Exxon Valdez oil spill restoration project final report (restoration project 00163, Appendix E). Exxon Valdez Trustee Council, Anchorage, AK

Suryan RM, Saba VS, Wallace BP, Hatch SA, Frederiksen M, Wanless S (2009) Environmental forcing on life history strategies: evidence for multi-trophic level responses at ocean basin scales. Prog Oceanogr 81:214-222

Trivers RL, Willard DE (1973) Natural selection of parental ability to vary the sex ratio of offspring. Science 179: 90-92

Vincenzi S, Mangel M (2013) Linking food availability, body growth and survival in the black-legged kittiwake Rissa tridactyla. Deep-Sea Res II 94:192-200

- Vincenzi S, Hatch S, Mangel M, Kitaysky A (2013) Food availability affects onset of reproduction in a long-lived seabird. Proc R Soc B 280:20130554, doi: 10.1098/rspb. 2013.0554

White JW, Rassweiler A, Samhouri JF, Stier AC, White C (2014) Ecologists should not use statistical significance tests to interpret simulation model results. Oikos 123: 385-388

- Wolf N, Mangel M (2008) Multiple hypothesis testing and the declining-population paradigm in Steller sea lions. Ecol Appl 18:1932-1955

Submitted: January 2, 2014; Accepted: August 17, 2014 Proofs received from author(s): October 30, 2014 